\title{
Carnets
}

Revue électronique d'études françaises de l'APEF

Première Série - 2 Numéro Spécial 10-11 | 2011

D'un Nobel l'autre

\section{Petits tours: representações do circuito turístico em Lawrence Durrel, David Lodge e Didier van Cauwelaert}

Isabel Peixoto Correia e Sandra Raquel Silva

\section{(2) OpenEdition \\ 1 Journals}

\section{Edição electrónica}

URL: http://journals.openedition.org/carnets/5749

DOI: $10.4000 /$ carnets. 5749

ISSN: 1646-7698

Editora

APEF

Edição impressa

Data de publição: 1 Janeiro 2011

Paginação: 225-242

Refêrencia eletrónica

Isabel Peixoto Correia e Sandra Raquel Silva, «Petits tours: representações do circuito turístico em Lawrence Durrel, David Lodge e Didier van Cauwelaert », Carnets [Online], Première Série - 2 Numéro Spécial 10-11 | 2011, posto online no dia 16 junho 2018, consultado o 22 abril 2019. URL : http:// journals.openedition.org/carnets/5749; DOI : 10.4000/carnets.5749

\section{(9) $(1) \Theta$}

Carnets est mis à disposition selon les termes de la licence Creative Commons - Atribution - Pas d'utilisation commerciale 4.0 International. 


\title{
PETITS TOURS: REPRESENTAÇÕES DO CIRCUITO TURÍSTICO EM LAWRENCE DURRELL, DAVID LODGE E DIDIER VAN CAUWELAERT
}

\author{
ISABEL PEIXOTO CORREIA \\ Universidade do Minho e Escola Secundária de Vila Verde \\ isabelpeixotocorreia@gmail.com \\ SANDRA RAQUEL SILVA \\ FCT, Universidade do Minho e Escola Secundária Camilo Castelo Branco \\ silva.sandraraquel@gmail.com
}

\begin{abstract}
Resumo
O grand tour cedeu, progressivamente, lugar a pequenos circuitos. As grandes paisagens inexploradas quase desapareceram. Ao grande aristocrata sucedeu o turista. O contacto com os autóctones não passa de um simulacro, amiúde encenado para conferir cor local. O exotismo desapareceu e a aventura acantona-se em actividades radicais - ou, até, na esfera virtual. À semelhança da rainha Charlotte, para quem a contemplação do quadro expressamente encomendado a Johann Zoffany, The Tribuna of the Uffizi, substituía a visita in loco à galeria florentina, os turistas a que faremos referência, a partir de três narrativas de Lawrence Durrell, David Lodge e Didier Van Cauwelaert, contentam-se em consumir os roteiros, as paisagens e a gastronomia de locais-bilhete postal. Em contrapartida, este tipo de férias propicia o estudo atento dos companheiros de viagem, pelo que a análise antropológica e sociológica se centra no homo turisticus (Lipovetsky) e constitui uma heterotopia (Foucault).
\end{abstract}

\begin{abstract}
The grand tour gave way, progressively, to the small circuits. The great untamed landscapes are almost gone. The great aristocrat paved the way to the tourist. Contact with the indigenous is but a simulation, often rehearsed to confer local flare. The exotic disappeared and adventure seeks refuge in extreme activities - or even in virtual reality. Just like queen Charlotte, to whom contemplating the painting commissioned to Johann Zoffany, The Tribuna of the Uffizi, replaced the in loco visit to the Florentine gallery, the tourists we shall mention, based on three novels by Lawrence Durrell, David Lodge e Didier Van Cauwelaert, limit themselves to the consumption of routes, landscapes and gastronomy of postcard places. Meanwhile, this holyday allows the careful study of the travel companion, thereby allowing the anthropological and sociological analysis to center in the homo turisticus (Lipovetsky), and thus constituting a heterotopy (Foucault).
\end{abstract}

Palavras-chave: viagem, circuito turístico, simulacro, heterotopia

Keywords: voyage, touristic circuit, simulation, heterotopy 
Dos três autores em análise, o mais nobelizável teria sido Lawrence Durrell, cujo nome foi várias vezes apontado como um favorito. Porém, a morte antecedeu a atribuição do Nobel. David Lodge tem contra si factores de peso: uma carreira académica prévia e a circunstância de não tratar problemas candentes do género humano. O seu sucesso editorial e a atracção pela paródia não oferecem garantias de que a cerimónia do Nobel demasiado próxima, se pensarmos nisso, dos colóquios que constituem o pano de fundo de alguns dos seus maiores sucessos - não viesse a ser, ela própria, objecto de paródia. Didier van Cauwelaert é um autor de sucesso em França, tendo recebido, em 1994, o Prémio Goncourt com Un aller simple. A sua obra é extensa e parece manifestar a intenção de focar assuntos da actualidade. Não recua perante temas tabu - criando personagens tão díspares como uma estrela de filmes pornográficos e uma fada que trabalha num hipermercado nem perante novos suportes, como o ecrã do telemóvel. O filme $A$ educação das fadas, de José Luis Cuerda, foi adaptado do livro L'éducation d'une fée. Por outro lado, as personagens e as temáticas veiculam preocupações sociais. O facto de as suas obras serem estudadas no âmbito do Francês Língua Materna e Estrangeira em diferentes países pode, por paradoxal que possa parecer, constituir um entrave a uma eventual atribuição do Nobel, já que resultaria numa sobreexposição mediática que a agenda oculta do júri do prémio, nos últimos anos, não parece contemplar ${ }^{1}$.

Centremo-nos, agora, nos livros e autores que seleccionámos, não apenas por se tratar de eventuais candidatos ao prémio Nobel, mas também pelo facto de, do ponto de vista temático, apresentarem perspectivas acerca da evolução cronológica que a viagem organizada sofreu dos anos 70 até aos anos 90 do século passado.

A partir de finais do século XVI, uma das etapas fundamentais da aprendizagem dos jovens aristocratas ingleses, o grand tour - viagem através da França, da Suíça e da Itália foi-se disseminando a camadas sociais cada vez mais abrangentes, dando origem a uma extensa lista de guias, mas também a algumas paródias, de entre as quais se destaca $A$ Sentimental Journey Through France and Italy by Mr. Yorick, do inglês Lawrence Sterne.

De então para cá, o grand tour continuou a exercer fascínio, manifestando-se em fenómenos espúrios como o ano sabático que muitos jovens norte-americanos abastados realizam antes de ingressar na Universidade; ou em epifenómenos como as viagens à Europa efectuadas por brasileiros ricos ${ }^{2}$; inter-rails concebidos pelas próprias companhias de caminho de ferro; cruzeiros; e circuitos turísticos. A massificação da viagem tê-la-á desvirtuado, e a sequência de obras que nos propomos apresentar vem demonstrá-lo.

\footnotetext{
${ }^{1}$ Nos últimos anos, a imprensa especializada aponta a prevalência, na atribuição do prémio, de critérios geopolíticos.

2 Leia-se, por exemplo, Leite Derramado, de Chico Buarque de Hollanda.
} 
Com efeito, Sicilian Carousel, publicado em 1977, assemelha-se a um diário de viagem que o escritor e diplomata Lawrence Durrell efectuou através da Sicília, integrando um circuito turístico epónimo adquirido numa agência de viagens. Tratando-se de uma autoficção, o narrador coincide com o autor empírico, como se depreende do episódio de reconhecimento no qual o prefeito francês se lhe apresenta ${ }^{3}$; ou, ainda, quando alude à redacção de um dos volumes do The Alexandria Quartet ${ }^{4}$, Justine.

O narrador, a vários títulos, um especialista, afirma que parte da sua subsistência advém do jornalismo de viagens ${ }^{5}$, tem profundos conhecimentos históricos e consciência de que os turistas são "modern pilgrims" (Durrell, 1977: 55), citando, ainda, um (proto)grand tour $^{6}$, bem como célebres livros de viagens, como Promenades en Rome, de Stendhal (Durrell, 1977: 88) e Viagem a Itália, de Goethe (Durrell, 1977: 39, 47, 184).

Sicilian Carousel (1976) é também uma peregrinação sentimental, no sentido em que o narrador evoca Martine Gainsborough, uma amiga que o convidara insistentemente a visitá-la na Sicília, pedido a que ele não acedeu. Mas Martine, entretanto, morrera, sendo as suas cartas um dos hipotextos da obra durrelliana. É ao longo do percurso que o narrador vai demonstrando a sua crescente insatisfação com os inconvenientes e limitações que este tipo de circuitos comporta.

O caso de Paradise News (1991), de David Lodge, é substancialmente diferente. Em primeiro lugar, trata-se de um relato ficcional, em que a crítica - assaz contundente - às viagens organizadas é um dos fios da trama narrativa, a par de outros mais característicos da narrativa lodgiana, como a investigação académica, o sexo ou a religião. Curiosamente, a investigação que um dos turistas leva a cabo tem a ver, precisamente, com a viagem como substituto do ritual religioso. Embora David Lodge desenvolva um aparato crítico sofisticado, a personagem principal, Bernard, não se integra no circuito a tempo inteiro, dadas as vicissitudes que a sua vida pessoal e familiar sofre. Ainda assim, vamos acompanhando o desenrolar de duas semanas de férias de vários ingleses no Havai. Nos dois decénios que separam a publicação destas duas obras, o número de viagens organizadas e de turistas, a mecanização e folclorização dos rituais turísticos e da autenticidade e genuinidade nativas, a pressão urbanística e ambiental, aumentaram exponencialmente, surgindo de forma crítica e mordaz na obra de Lodge.

A matriz de Un aller simple (1994), de Didier van Cauwalaert, também difere das anteriores. A viagem surge como falso expatriamento de um falso cigano para o seu (falso) país de origem, Marrocos. A viagem organizada manifesta-se lateralmente. Contudo, Un

\footnotetext{
3 "Be assured. Your anonymity is safe with me and my wife. Nobody shall ever know that Lawrence Durrell is with us." (Durrell, 1977: 61)

4 "I showed her a half-finished novel called Justine." (Durrell, 1977: 49)

${ }^{5}$ Cf. 18

6 "Somehow there was a tug towards Greece, and the young Romans must have made a sort of Grand Tour of the now ruined and blasted land" (Durrell, 1977: 73)
} 
aller simple entabula um diálogo com as duas obras anteriores, às quais parece oferecer a única solução viável: uma ruptura radical. A guia-socióloga, cuja tese versa sobre a agressividade em grupo, abandona os turistas da "Morocco Tours", quando estes se sublevam contra si e provocam uma escaramuça com o grupo da "Oasis Travel". A narrativa, primeiro oral e depois escrita, surge como a verdadeira viagem e é na Lorraine, numa localidade paradigmaticamente anti-turística e anti-exótica, que os dois narradores se fundem.

\section{Sicilian Carousel: os primórdios do pacote turístico}

A estrutura narrativa de Sicilian Carousel decorre do percurso pré-estipulado no circuito turístico empreendido pelo narrador ${ }^{7}$. Embora o texto se inicie com uma preterição ("nobody has ever had better reasons than I for not visiting the island." - Durrell, 1977: 17), uma prolepse que tece uma apreciação normalmente remetida para o explicit ("but you seem to be enjoying it very much. I was." - idem: 17) e um excurso alusivo à morte de Martine e à amizade que a unia ao narrador, a breve trecho, a narrativa seguirá uma cronologia sequencial.

A convite de um editor de Nova lorque, que the solicita artigos de viagem sobre a ilha, o autor empírico visita uma agência de viagens e escolhe o "Carrossel Siciliano", circuito aconselhado pelo seu agente habitual. Face à afirmação "The thing for you [...] is the Sicilian Carrousel - every advantage from your point of view. You will have Roberto as guide and a fine bus" (Durrell, 1977: 20), a reacção é incisiva: "My soul contracted." - (Durrell, 1977: 15). O cepticismo do narrador não se fica por aí: "I did not need French commercial prose to excite me." - Durrell, 1977: 16. Pese embora a profissionalização crescente dos circuitos turísticos, mais patente nas duas outras obras, o grupo que integra o Carrossel já é identificado com pequenas rosetas (Durrell, 1977: 23), participa em degustações (Durrell, 1977: 159), e partilha com os restantes elementos do grupo música dos respectivos países (Durrell, 1977: 181).

O narrador inicia uma observação atenta dos viajantes, os quais, embora possam ter como modelo pessoas reais, formam um sistema de personagens coerente e verosímil (passe o paradoxo). Simpatiza de imediato com o coronel Deeds, descobrindo afinidades e percursos de vida semelhantes, ou, até, coincidentes. A descoberta de que Deeds conhecera Martine propicia uma descrição alternativa desta. Deeds, tal como Martine, alude aos privilégios de classe da amiga do narrador, que a própria tenta minimizar, graças,

\footnotetext{
7 "Arrival $\rightarrow$ Catania $\rightarrow$ Syracuse $\rightarrow$ Agrigento $\rightarrow$ Selinunte $\rightarrow$ Erice $\rightarrow$ Segesta $\rightarrow$ Palermo $\rightarrow$ Taormina"
} 
precisamente, a um tipo de viagem que tem por modelo um grand tour voluntariamente despojado:

I found [...] that I was becoming hopelessly spoiled by money, birth and upbringing. I decided to stop being a society fashion-plate and start trying to realize myself. But how, when you haven't much talent? I started with this journey, which I did entirely by bus and train. I avoided all the Embassies and all my compatriots. (Durrell, 1977: 25)

Desde logo, o narrador partilha com Deeds as suas apreensões: "I shall loathe the group, I feel it." (idem: 25). Tipicamente, os turistas são acolhidos "by a man with a hat reading 'Guide'." (Durrell, 1977: 29), sentam-se em lugares previamente marcados e devidamente assinalados e começam a viajar num pequeno autocarro vermelho, conduzido por um motorista eficaz. O grupo é heterogéneo, constituído por ingleses, franceses, alemães, japoneses e italianos. Apesar da heterogeneidade do grupo, em breve este começa a "degelar" (Durrell, 1977: 34).

O guia, Roberto, fora "a university lecturer in history; but the boredom of academic life with its endless intrigues had sent him in search of something more suitable to a lively nature. He had found it in becoming guide, philosopher and friend to the travellers on the Carousel." (Durrell, 1977: 35).

A dado ponto, Roberto é substituído por um guia local, possivelmente "a university professor in classics who had become bored with retirement" (Durrell, 1977: 90). Ambos são competentes, mas Roberto tem consciência das limitações do seu ofício, "saying that one was always telling people something they already knew or something they did not wish to know." (Durrell, 1977: 42). Com efeito, enquanto a família "Microscópio" se desinteressa facilmente das explicações, outros turistas preparam-se cuidadosamente, consultando o Guide Bleu (Durrell, 1977: 45), o Baedeker (Durrell, 1977: 101), outros guias da ilha em inglês e francês (Durrell, 1977: 48); e ainda Goethe (Durrell, 1977: 39, 47, 184) ou Stendhal (Durrell, 1977: 88).

Martine já advertira epistolarmente o narrador: "The present guide lacks poetry, and the existing starsystem devised for ruins is rather unsatisfactory" (Durrell, 1977: 48). Deeds encontra uma explicação para a insuficiência classificatória dos guias: "its the sheer multiplicity of the subject matter. The damned island overflows with examples of the same type of thing." (Durrell, 1977: 48). Para obviar a esta dificuldade, Deeds concebe o seu próprio sistema de classificação, com "symbols which strongly suggested the Sikel alphabet or Linear B. Intrigued, I asked him what they represented [...] Together they form the word Moss. $\mathrm{M}$ is for must, $\mathrm{O}$ is for ought really, $\mathrm{SH}$ is for should really, and $\mathrm{SK}$ is for skip." (Durrell, 1977: 78). 
Se a tudo isto juntarmos as cartas de Martine, que vão pontuando a narrativa, bem como as numerosas digressões histórico-filosóficas, da autoria do narrador, verifica-se que Sicilian Carousel constitui um texto híbrido, simultaneamente guia turístico polifónico e narrativa literária convencional. Tanto assim é que, ao longo da obra, deparamos com descrição de personagens, intrigas e desgostos amorosos, dilemas existenciais ("the Anglican Bishop who had developed Doubts." - Durrell, 1977: 34), ou enigmas (as causas da fuga e morte "programada" de Beddoes). Naturalmente, as motivações que levam os turistas/personagens a viajar vão-se desvendando lentamente: "In the case of the officer Deeds you know his young brother is buried in that little cemetery where he told us about the locust-beans - one the commandos he mentioned." (Durrell, 1977: 216). Roberto tem uma explicação mais abrangente: “Travelling isn't honest. Everyone is trying to get away from something or else they would stay at home" (Durrell, 1977: 216).

O registo quase onírico do narrador revela o cariz autoficcional do texto: "(I am talking in my sleep to Martine with one half of my mind; with the other I am trying to rough in the outlines of the pocket history which she had once demanded for her children.)" (Durrell, 1977: 68). "[I] would build something more like a companion to landscape than a real history." (idem). Num dos seis poemas que se encaixam na narrativa, "Taormina", pode lerse o seguinte: "She ${ }^{8}$ rides at last to lend/ A form and fiction to our loving wish." (Durrell, 1977: 206).

Se uma pesquisa aos nomes de Martine ou do conde francês se revela infrutífera, é de supor que, em traços gerais, a viagem de Durrell terá acontecido, mas que este salvaguardou a identidade dos seus acompanhantes/personagens, cumprindo assim o desiderato de Martine.

Michel Le Bris, em "Une littérature-monde", refere-se ao travel writing como um género híbrido, e transcreve a afirmação de Chatwin, segundo o qual se trata de "appliquer au réel les techniques de narration du roman pour restituer la dimension romanesque du réel." (Le Bris, 1997: 27; Le Bris, 2004: 60).

Ora, o real em que se insere Sicilian Carousel corresponde à fase II da sociedade de consumo de massa, de acordo com a taxonomia de Lipovetsky ${ }^{9}$. "Pela primeira vez [ao longo das três décadas do pós-guerra] as massas acedem a uma procura material mais psicologizada e mais individualizada, a um modo de vida (bens duradouros, actividades de lazer, férias, moda), até então exclusivo das elites sociais." (Lipovetsky, 2007: 29). Os turistas e o guia têm consciência das limitações do turismo programado. Roberto afirma,

\footnotetext{
${ }^{8} \mathrm{~A}$ amiga ausente.

9 "Marcada por um excepcional crescimento económico, pela subida do nível de produtividade do trabalho, bem como pela extensão da regulação fordiana da economia, a fase II corresponde àquilo que chamámos de "sociedade da abundância». Triplicando ou quadruplicando o poder de compra dos salários, democratizando os sonhos do Eldorado consumista, a fase II apresenta-se como um modelo puro da "sociedade do consumo de massa»." (Lipovetsky, 2007: 28)
} 
sarcasticamente, "But we will do the two essential things so that you can tell your friends if they ask that you have seen the Duomo and St. Nicolo." (Durrell, 1977: 42) Os turistas são comparados a um rebanho de ovelhas "hardly more intelligent either, you might have thought, to watch us mooching about." (Durrell, 1977: 46)

Considerando que a Grécia se tornara "o modelo do vulgar" (Durrell, 1977: 73), e protestando "petulantly against the tourism of his day" (idem), Pausânias inspira ao narrador durrelliano a imagem do "little red bus with Mario at the wheel, and the twenty or so captives of tourism tip-toeing around monuments they do not comprehend with a grave piety they do not feel." (idem: ibidem). Deeds contribui com uma "pequena homilia" (Durrell, 1977: 184) para uma consciência crítica do turismo programado: "Nowadays [...] one drives straight up to these places by bus and so one doesn't get the pleasure of the effort. One just rapes them." (idem). Este trecho - onde os vocábulos fake e pretend surgem quatro vezes, numa antecipação da teoria baudrillardiana do simulacro - é sintetizado na afirmação do narrador: "And suddenly I felt nothing but pure hate for the Carousel" (Durrell, 1977: 184). Como se não bastasse, os turistas deparam com um casal de velhos incomparavelmente distintos recitando grego antigo. A "quiet aristocratic commiseration" (Durrell, 1977: 185) e o desdém com que a personagem masculina profere "'Poor tourist scum" (Durrell, 1977: 185) constitui o culminar da atitude crítica face às viagens organizadas de toda a obra.

Além disso, os "pacotes de viagens" são heterotopias ${ }^{10}$. "it is no use pretending that travelling in a bus does not gradually begin to feel cramping, restricting." (Durrell, 1977: 163). Guia, turistas e motorista têm picos de humor, amuam ${ }^{11}$, embora também experimentem momentos de harmonia. Em todo o caso, todos parecem partilhar uma atracção por viagens assaz diferentes ("And I think we poor tourists felt a subconscious tug towards the freedom and adventure of the Romany life - it contrasted so radically with our own." (Durrell, 1977: 164).

A síntese surge via Deeds: "This trip is only a spot reconnaissance." (Durrell, 1977: 198). Mais tarde, o narrador principal apropria-se desta ideia e desenvolve-a, dizendo

I realized then that Sicily is not just an island, it is a sub-continent whose variegated history and variety of landscapes simply overwhelms the traveller who has not set aside at least three months to deal with it and its overlapping cultures and civilizations.

(Durrell, 1977: 215)

\footnotetext{
${ }^{10}$ Em "Des espaces autres" (Foucault: 1984, 46-49), Michel Foucault define os espaços heterotópicos como: "[certains emplacements qui] ont la curieuse propriété d'être en rapport avec tous les autres emplacements, mais sur un mode tel qu'ils suspendent, neutralisent ou inversent l'ensemble des rapports qui se trouvent, par eux, désignés, reflétés ou réfléchis.", constituindo uma "espèce de contestation à la fois mythique et réelle de l'espace où nous vivons "e sendo "une constante de tout groupe humain".

${ }^{11}$ Parecem "a gaggle of wattle-wagging turkeys." (Durrell, 1977: 154); "I felt a twinge of regret; but I also felt a twinge of relief - for it would have been unthinkable to extend this mode of travel a longer space of time without coming to dislike, even to hate, it." (Durrell, 1977: 199).
} 
Numa mise en abyme ao vulcão, o explicit alude à combustão das cartas de Martine e termina com o narrador em meditação junto ao Etna. A peregrinação sentimental havia chegado ao fim.

\section{Paradise News: a paródia}

A estrutura narrativa de Paradise News, do escritor e académico inglês David Lodge, segue pari passu um grupo de turistas que adquiriu um pacote de férias para o Havai. $O$ incipit remete imediatamente para uma rejeição da viagem organizada, emitida por Leslie Pearson, gerente da Travelwise Tours: "What do they see in it, eh? What do they see in it?" (Lodge, 1992: 3). O questionamento será repetido um pouco mais tarde ${ }^{12}$. Desta feita, porém, a pergunta obtém uma resposta que, de alguma forma, lembra o acrónimo Moss criado pelo coronel Deeds. Aqui, Trevor Connolly refere-se cinicamente a três esses (sol, sal e sexo). Está dado o tom parodístico do texto. Voltando ao sistema classificatório de Lipovetsky, passamos para a fase III do hiperconsumo, caracterizada pela emergência do turismo enquanto primeira indústria mundial (Lipovetsky, 2007: 53), em que "a civilização do objecto foi substituída por uma «economia da experiência», das actividades de lazer e do espectáculo, do jogo, do turismo e da distracção..." (Lipovetsky, 2007: 54), já para não mencionar o "simulacro da aventura" (Lipovetsky, 2007: 58).

O carácter heterotópico das viagens organizadas - que, no decurso da obra, não se virá a verificar, dados os vários pontos de fuga introduzidos na narrativa ${ }^{13}$ - é dado nas observações feitas pelos dois representantes da agência. "They [passengers] are still relatively fresh: their bright, casual clothes are clean and pressed, their cheeks smooth from the recent application of razor or make-up, their hair groomed and glossy." (Lodge, 1992: 34); "Eighteen and a half hours cooped up in one of those oversized sardine cans? Must be mad. They're all mad, if you ask me." (Lodge, 1992: 5). O diálogo destas duas personagens, que cedo irão desaparecer (embora façam uma breve aparição no vídeo final), constituirá o pretexto para a primeira descrição dos participantes no pacote de viagem.

À parafernália que os turistas costumam transportar consigo - que em Sicilian Carousel era apenas constituída por "Binoculars, scarves, Thermos, flasks, picnic baskets and cameras; we carried all this lumber with us like modern pilgrims do" (Durrell, 1977: 55) adiciona-se, agora, um acessório de monta, uma câmara de vídeo portátil, que registará quase todos os momentos-chave das férias do casal Everthorpe, dando origem a diversas

\footnotetext{
12 "What do they see in it? he says again. "What are they after?" (Lodge, 1992: 4)

${ }^{13}$ Ainda assim, quase no final da obra, Bernard descreve os momentos que passa no Waikiki Surfrider como "a kind of capsule, a bubble in time and space, this room, where there's no gravity, where the normal rules of life are suspended." (Lodge, 1992: 349-350)
} 
peripécias e culminando num vídeo caseiro exibido quase no final da narrativa, permitindo, assim, completar analepticamente todas as peripécias sofridas pelos turistas.

O grupo também é constituído por personagens assaz heterogéneas. A família Best, por exemplo, assemelha-se, pelas suas queixas e reclamações ${ }^{14}$, à família Microscópio da narrativa durrelliana. As duas inglesas, Dee e Sue, desempenham, no seu conjunto, função análoga à de Miss Lobb. E, embora Roger Sheldrake pudesse desempenhar o mesmo papel que o narrador de Sicilian Carousel, sendo objecto das conjecturas dos operadores turísticos - "he's on a freebie. Usually it means a journalist. Travel writer. - Lodge, 1992: 7) na prática, ele constitui um pretexto para inserir na narrativa análises económicas, sociológicas e antropológicas ancoradas em teorizações efectivas de investigadores dessas áreas. Porém, o académico é objecto de uma paródia, como frequentemente sucede nas narrativas lodgianas. Aliás, se bem que integre o circuito turístico com privilégios especiais (limusina, garrafas de champanhe, fruta e flores no quarto), o investigador põe-se, desde logo, sob a égide oculta de Lévi-Strauss ${ }^{15}$, dizendo a Bernard: "I never go on holiday [...] I always hated holidays, even as a kid." - Lodge, 1992: 75-76. Num trecho posterior, redige um "Draft intro" (Lodge, 1992: 242), no qual cita, de forma explícita, este antropólogo.

Segundo Roger Sheldrake, "sightseeing is a substitute for religious ritual." (Lodge, 1992: 75). Sheldrake constitui, pois, a par de Bernard e de Yolande, um narrador informado, desvendando, ao longo da obra, a realidade das viagens organizadas que prometem o paraíso, mas, na prática, o destroem ${ }^{16}$. O mote é dado ainda em Inglaterra, quando Leslie inicia a longa metáfora continuada da desconfiguração do paraíso que a obra, no seu todo, empreende: "We're like guardian angels, wafting them over to the other side." (Lodge, 1992: 8). São, porém, anjos-da-guarda cépticos, que caracterizam o seu rebanho como "gente pirosa" (Lodge, 1992: 5) e afirmam que "You got to keep going further and further to get away from the Joneses" (Lodge, 1992: 5$)^{17}$. Sendo Sheldrake, cujo livro seguinte versa acerca do turismo e o mito do paraíso, quem elenca de forma obsessiva todas as ocorrências do vocábulo, será Bernard o mais expedito a encontrá-las e a explicá-las.

O grupo completa-se com três casais, o primeiro dos quais jovem e em lua-de-mel, mas desavindo; um segundo, que documenta obsessivamente a sua segunda lua-de-mel, de câmara em riste e poses estudadas; e, por último, um casal de idade que viaja a convite do filho, para conhecer a sua "pessoa especial", que não é a nora que esperavam, mas um surfista australiano. Os dois últimos casais encontram afinidades no estilo de vida, designadamente no que diz respeito à fuga aos impostos. A familiaridade entre os dois

\footnotetext{
14 "Some customers are never satisfied, says Leslie. I know the type. Tell'em a mile off." (Lodge, 1992: 13)

${ }^{15}$ O qual inicia Tristes trópicos com a frase "Odeio as viagens e os exploradores." (1986: 11)

16 "Tourism is wearing out the planet." (Lodge, 1992: 78). Cf. também p. 79.

${ }^{17}$ É essa também a temática satirizada por Claire Bretécher em "Robinson". (Bretécher, 2007: 34-35)
} 
maridos torna-se mais patente a partir do momento em que ambos descobrem um avatar de pub inglês em pleno Havai.

Um dos motivos recorrentes na obra é a questão dos simulacros e da falta de autenticidade. Do ponto de vista arquitectónico, além do pub inglês, assinale-se a existência de dois escritórios, que constituem uma "simulation of office life in some commercial capital of the northern hemisphere." (Lodge, 1992: 198), o de Mr. Bellucci e o de Simcock Yamaguchi, cuja sala de compra e venda é um simulacro de Wall Street... (Lodge, 1992: 222) e de um shopping vitoriano (Lodge, 1992: 231). Em contraponto a este kitsch (a palavra surge explicitamente na narrativa), descreve-se o hotel Moana como "the real thing, a Beaux Arts building in wood of real grandeur and distinction, now beautifully restored, with polished hardwood floors and William Morris textiles." (Lodge, 1992: 232)

As alusões ao Havai como Disneylândia surgem, inclusivamente, no discurso de personagens mais ou menos insuspeitas, como Sue, que designa, assim, o Centro Cultural Polinésio (Lodge, 1992: 133). Naturalmente, Yolande refere-se ao Havai como a "Fantasilândia" (Lodge, 1992: 233), de onde tudo o que era constitutivo - e, para uma feminista, verdadeiramente atraente na cultura polinésia - da utopia do "free love and nudity." (Lodge, 1992: 234) foi rechaçado pelos marinheiros e pelos missionários.

Por último, refira-se um simulacro recorrente nas viagens organizadas reais e literárias, ou seja, a cerimónia tradicional (neste caso, o luau), através da qual se demonstra que o exótico e o autêntico, procurados pelos turistas, são meros sucedâneos:

It had been a bit of a shock at first to discover that something like a thousand people had been bused to Sunset Cove for the evening, to be seated at plastic topped refectory tables, laid out in rows as if in some kind of refugee camp. (Lodge, 1992: 137).

Cumpre, agora, fazer novamente um ponto da situação quanto às estratégias narrativas. Como vimos, em diversos momentos, deparamos com os pontos de vista, ou mesmo fragmentos textuais, da responsabilidade das personagens-narradores Bernard Walsh e Roger Sheldrake, que se demarcam da representação do Havai enquanto paraíso e que se posicionam nos antípodas do homo turisticus e do homo festivus. (Lipovetsky).

Yolande e Ursula, tia de Bernard, também assumem uma voz crítica ao longo da narrativa. Yolande, com formação académica adquirida nos Estados Unidos, residente no Havai desde que o ex-marido, geógrafo climatologista, aceitou o cargo de professor associado na Universidade do Havai ${ }^{18}$, toma uma posição crítica quanto a este país de sonhos, ideal para pessoas pirosas passarem a lua-de-mel. Num jantar informal com

\footnotetext{
${ }^{18}$ Lewis Miller conheceu Roger Sheldrake numa “interdisciplinary conference on tourism.” (Lodge, 1992: 342).
} 
Bernard, Yolande afirma que "The history of Hawaii is the history of loss. [...] Paradise stolen. Paradise raped. Paradise infected. Paradise owned, developed, packaged, paradise sold." (Lodge, 1992: 177) ${ }^{19}$. Esta técnica textual dá azo ao desenvolvimento de uma teoria histórica, sociológica, urbanística e antropológica do Havai visto por uma residente particularmente informada.

Já Ursula desempenha o papel de testemunha do estilo de vida que os americanos, voluntariamente radicados em Honolulu, levavam em meados do século XX: "How I wish you'd come before, when I was well!" (Lodge, 1992: 261). É ela também que alude a aspectos práticos como o chamado "paradise tax", que resulta de quase tudo ser importado. (Lodge, 1992: 121)

Além destas quatro instâncias narrativas críticas (que, nos casos de Bernard e de Sheldrake, se traduzem não apenas nos diálogos, mas também em fragmentos textuais, notas, listas e diários), no final da segunda parte, há uma quebra tipográfica que permite a inserção no texto da correspondência enviada pelos restantes turistas. Desta maneira, instaura-se a polifonia da narrativa, que culminará no visionamento do vídeo caseiro dos Everthorpe. Parte do filme, exibido em modo acelerado, constitui uma espécie de mise en abyme do circuito percorrido pelo grupo, que é elidido ao leitor, dado que este acompanhou as peripécias vividas por Bernard:

As if sensing the audience's restiveness, Beryl herself requested Brian to 'gee it up a bit', and he rather reluctantly pressed the fast-forward button on his remote control. This certainly had the effect of making the film more amusing. At Pearl Harbor, a naval cutter surged out towards the Arizona with the speed of a torpedo boat, and disgorged a cluster of tourists who swarmed all over the Memorial for a few seconds before being sucked back into the vessel and returned abruptly to shore. (Lodge, 1992: 338)

Assim, o vídeo aponta para a circularidade da narrativa, ou, se quisermos, do circuito que as personagens realizaram, tal como acontecia no Carrossel Siciliano. Sheldrake alude à circularidade dos roteiros turísticos, particularmente visível quando o território a visitar é uma ilha, seja ela a Sicília ou uma ilha havaiana. A metáfora a que recorre é a da correia de transmissão, destinada a "conveying people from one tourist trap to the next, one lot leaving as the other lot arrives. The same applies to cruise itineraries, charter flights" (Lodge, 1992: 334). Comparação análoga havia sido tecida por Bernard aquando do transbordo em Los Angeles: "[The passengers] stood dumbly on moving walkways, like objects on a conveyor belt" (Lodge, 1992: 66).

\footnotetext{
${ }^{19}$ Note-se a convergência do verbo "to rape" nos textos de Durrell e Lodge em escopo.
} 
Em maior ou menor grau, todas as personagens explanam a sua decepção face ao pretenso paraíso. Ainda assim, perante um novo vídeo promocional exibido pela Travelwise, uma parte dos turistas deixa-se hipnotizar com promessas de um novo paraíso, dando assim razão à teoria de Roger Sheldrake, segundo a qual "the mere repetition of the paradise motif brainwashes the tourists into thinking they have actually got there, in spite of the mismatch between reality and archetype." (Lodge, 1992: 163)

A intenção de Sheldrake, ao iniciar a viagem, era desconstruir a colagem da ideia de paraíso aos pacotes de férias, ideia essa que é declinada por várias personagens em diversos passos da narrativa. Para o investigador, as férias não passam de um ritual supersticioso que surgiu em força "just as religion went into decline. It's the new opium of the people, and must be exposed as such." (Lodge, 1992: 79). Aproveitando todas as benesses que a agência de viagem, julgando que ele é jornalista (Lodge, 1992: 343), Ihe concede, afirma que fará ao turismo "what Marx did to capitalism, what Freud did to family life." (Lodge, 1992: 76). A sua tese será revista "Oh, I've rejigged the thesis of that, to some extent. [...] I've decided that the paradise model is inevitably transformed into the pilgrimage model under the economic imperatives of the tourist industry." (Lodge, 1992: 334).

Roger Sheldrake nunca abandona a postura e o discurso de académico, o que propicia a inserção na narrativa de dados concretos e objectivos sobre a evolução do turismo no Havai ${ }^{20}$. Não obstante, é no monólogo interior e nas conversas que Bernard entabula com as outras personagens que surgem as perspectivas mais interessantes e originais acerca do turismo de massas. Na verdade, ele apenas opta pela modalidade pacote de viagens por este ser o meio mais barato de visitar Ursula, a sua tia doente em fase terminal. As reflexões de Bernard situam-se, por inerência de formação, na esfera da Teologia e da Literatura, assemelhando-se, em certas passagens, ao narrador durreliano ${ }^{21}$. Mesmo as suas observações iniciais, destituídas de intuitos académicos, revelam-se mais fundamentadas do que as de Sheldrake ${ }^{22}$. É Bernard quem explana, sem ostentar erudição, as teorias mais interessantes acerca do paraíso, do ponto de vista teológico, literário e vivencial.

\footnotetext{
20 "In 1988 approximately 6.1 million tourists visited Hawaii spending 8.14 billion dollars and staying for an average of 10.2 days. This compared with 4.25 million visitors in 1982, and only 0.7 million visitors in 1965 . The step rise in the volume of visitors was clearly related to the introduction of the jumbo jet in 1969" (Lodge, 1992: 56)

21 "His education, his work, his whole life and outlook, had been imprinted with the shape of a much smaller and more populous sea, the Mediterranean. How far had the early growth of Christianity depended on the assumption of believers that they lived at the "centre of the world'?" (Lodge, 1992: 31)

22 "[...] Bernard glanced through a heap of brochures. They seemed extraordinarily repetitive. [...] Majorca looked the same as Corfu and Crete looked the same as Tunisia. [...] Like so much else, the popular concept of holiday seemed to have mutated in his lifetime. [...] This idea of ordering a fortnight's standardized bliss from a printed catalogue was strange to him, though he could see the convenience of it, and the prices seemed very reasonable." (Lodge, 1992: 32-33)
} 
Com efeito, após exaustivas perspectivas críticas, oriundas das diversas personagens, que completam a visão do Havai como uma neo-disneylândia, Bernard conclui com uma perspectiva mitigada, ao citar Notícias para o Oráculo de Delfos de Yeats e comentando: "The Neoplatonics assumed there was no sex in heaven [...] Yeats thought he had news for them." (Lodge, 1992: 340)

Tanto em Sicilian Carousel como em Paradise News, há duas personagens que sofrem dilemas de fé e ambos encontram, graças à sensualidade, uma dimensão que os reconcilia, Bernard dixit, com o festim da vida (Lodge, 1992: 340). Apesar da crise de fé, Bernard é teólogo e discute com Ursula questões religiosas (uma das temáticas recorrentes na obra lodgiana). Dado que Ursula está prestes a morrer, ambos discutem a vida depois da morte, o que opera a ligação ao tema do paraíso, não já o paraíso terreno, mas o seu referente religioso. Bernard explana teorias dos novos teólogos, que confundem a tia. Por isso, ele simplifica, aludindo às "últimas quatro coisas" (Lodge, 1992: 259) do catecismo, linguagem que, para Ursula, é perceptível: "Death, Judgement, Hell and Heaven" (idem). Na aula que lecciona no fim da narrativa, Bernard retoma e complexifica a teorização, nomeando, explicitamente, os teólogos que subjaziam à conversa (Lodge, 1992: 352-356). Bernard não recupera a fé e recusa definitivamente o conceito de "sobrevivência do indivíduo à própria morte" (Lodge, 1992: 352), ou seja, a ideia de paraíso. Porém, admite um "humanismo secular", que deriva do cristianismo. (Lodge, 1992: 355)

É Bernard, pois, quem opera a fusão de quatro temáticas, aparentemente desligadas entre si, que percorrem a narrativa: Religião, Turismo, Morte e Doença, Amor e Sexo. As dificuldades com que se debate nestes quatro domínios serão resolvidas. Com efeito, encontra a serenidade numa ética cristã, encara o Havai como uma terra não desprovida de encanto (vejam-se a ida à praia (Lodge, 1992: 204) e a vista do mar a partir do alto da colina em Diamond Head (Lodge, 1992: 318), de onde decorre também a perspectiva pacificada da morte (para si e para Ursula) e, finalmente, a resolução dos seus dilemas sexuais e afectivos.

Tão complexas como este entrecruzar de temas são as várias fundamentações para o título da obra.

Numa primeira ocorrência, ele surge como título de uma publicação grátis que Bernard retirou de um expositor no aeroporto (Turismo).

$\mathrm{Na}$ segunda ocorrência, Bernard refere-se ao seu ofício de padre, numa longa e complexa comparação que alia religião e turismo: "The Good news is news of eternal life, Paradise news. For my parishioners, I was a kind of travel agent, issuing tickets, insurance, brochures, guaranteeing them ultimate happiness." (Lodge, 1992: 190) (Religião).

Por fim, a carta que Yolande Ihe escreve, narrando a morte de Ursula (Doença e Morte) e a sua decisão de o visitar, não pondo de parte a hipótese de virem a viver juntos 
(Amor e Sexo), constitui para Bernard uma espécie de notícia do paraíso. (Lodge, 1992: 369).

Desta forma, as quatro temáticas - Religião, Turismo, Morte e Doença, Amor e Sexo - unem-se graças a uma utopia comum, embora revestida de aspectos muito diferentes: o Paraíso. Um olhar ingénuo para qualquer uma destas questões, tem-no como horizonte possível. $\mathrm{Na}$ acepção religiosa tradicional, constitui a recompensa; no turismo, é promessa; na morte, é salvação; no amor, é esperança.

\section{Un aller simple: a recusa da viagem organizada}

O narrador de Un aller simple é uma personagem a quem foi retirado o enquadramento familiar. Adoptado por um cigano que atropelou e matou os seus pais, Aziz, cujo nome resulta de uma corruptela da designação do carro em que viajavam (Ami 6), é desenraizado e desterritorializado. Vivendo no meio dos ciganos desde então, Aziz foi sempre considerado um gadjo, razão pela qual é vítima de uma trama que envolve a sua família de adopção, um joalheiro da Place Vendôme e as autoridades francesas, as quais o vão utilizar como exemplo de repatriação humanitária.

Com a escolaridade incompleta, vivendo de expedientes na periferia de Marselha, com um nome de ressonância árabe mas inventado quase aleatoriamente, a ninguém ocorre que Aziz não seja, efectivamente, magrebino. A viagem que vai empreender é, pois, completamente diferente das atrás analisadas. Se as duas primeiras partem de uma desvirtuação burguesa do ideário do Grand Tour, esta é uma viagem forçada, ditada por uma agenda política, dado que nenhum dos clandestinos até então aprisionados pela polícia revelava o seu local de origem. Aziz é expatriado por três motivos: os seus falsos papéis identificam-no como marroquino, é fotogénico e não parece árabe, propiciando boas fotografias para a reportagem simpática (van Cauwelaert, 1994: 40) que a Paris-Match iria fazer sobre ele ${ }^{23}$. Por último, Aziz é oriundo de Marselha "Et samedi l'émission 'Marseille, ville arabe' a fait trente pour cent de parts de marché, alors c'est d'ici qu'on lance l'opération" (van Cauwelaert, 1994: 33). Desta forma, o governo lança uma operação de charme destinada a contentar a opinião pública e a comunicação social no que se refere às questões levantadas pela imigração ilegal em França.

Assim, para Aziz, esta viagem é um pseudo-expatriamento. Para Jean-Pierre Schneider, o "attaché humanitaire" que o acompanha, trata-se de uma viagem de trabalho forçada, quer do ponto de vista pessoal, quer do ponto de vista profissional. Na verdade,

\footnotetext{
${ }^{23}$ De acordo com Pignol, o polícia que é seu amigo de infância, "comme par hasard, ils [...] prennent un qui a plus l'air d'un corse que d'un árabe. Comme ça c'est moins raciste!” (van Cauwelaert, 1994: 36).
} 
Schneider descobrira que o seu superior hierárquico o tinha incumbido desta missão, porque se tinha envolvido com a mulher dele.

É a partir do momento em que Schneider perde o contacto telefónico com a França, ou mais concretamente, com a mulher, que encara a viagem sob um outro ponto de vista. Inicialmente, tratava-se, apenas, de conduzir Aziz ao seu pretenso território de origem, "car le seul moyen de stopper le flux migratoire en provenance du Maghreb est de vous construire un avenir chez vous, par une vraie politique d'incitation au développement, tant sur le plan industriel que sur le plan des ressources humaines..." (van Cauwelaert, 1994: 33). Para a personagem, trata-se de uma maçadora tarefa burocrática. Porém, ainda no decurso da viagem, Aziz desperta no "attaché humanitaire" uma vontade de evasão.

Com efeito, apesar da sua baixa escolaridade, ele é o que se denomina homem de um só livro. Neste caso, trata-se de um Atlas des Légendes du Monde, que conhece de cor e utiliza como uma bíblia, citando as suas "parábolas" e usando-as como norma de vida, para uso próprio e alheio.

Desenraizado, é nas histórias que conta que Aziz encontra um território: "j'étais en route dans les nuages vers un pays inconnu où j'avais planté ma légende en guise de racines” (van Cauwelaert, 1994: 51) e, até, uma vocação: “il m’avait déjà réinséré: j'étais conteur arabe" (van Cauwelaert, 1994: 52). Entre Aziz e Jean-Pierre Schneider desenvolvese uma relação com carácter simbiótico, uma vez que o último tem absoluta necessidade de sonho e evasão para olvidar as frustrações matrimoniais, o malogro das ambições de escrita e a traição às origens familiares. Apesar da dependência das histórias de Aziz, Schneider mantém a ilusão da sua superioridade, daí o título que concebe para o livro que pretende escrever: Le Bagage accompagné. O attaché humanitaire é, pela amostra do seu discurso falado e escrito, excessivamente idealista e propenso a lugares-comuns. Embora Schneider intente fazer uso da história de Aziz, independentemente de se tratar de uma história verdadeira ou de uma efabulação, será este a apropriar-se do "Carnet de mission", do manuscrito, e, inclusivamente, da família daquele.

Ainda em Marselha, Aziz percepciona as similitudes entre uma França proletária e marginal e Marrocos. A partir do momento em que entra no avião, essas semelhanças acentuam-se. As temáticas abordadas por escritores marroquinos de segunda geração como Fouad Laroui - que se prendem com o facto de se sentirem estrangeiros quer no país de origem, quer no território de acolhimento, encontram aqui um paralelo a contrario. Referimo-nos ao francês como língua veicular e ao desconhecimento da língua pretensamente materna, à ignorância face às tradições de um e outro país (veja-se o facto de Aziz se servir da mão esquerda para comer, comportamento considerado indigno em Marrocos). Ainda assim, tem consciência de que o comportamento humano apresenta regularidades, e assim é que considera que a multidão em Rabat "ressemblait à celle de 
Marseille, à part la couleur des uniformes" (van Cauwelaert, 1994: 58), e trata como colegas os vendedores marroquinos. (van Cauwelaert, 1994: 65).

Por conseguinte, a forma como os narradores das três obras viajam põe-nos em contacto com duas manifestações do Outro. Nos meios de transporte "sociopètes" (referimonos à categoria teorizada por T. S. Hall em La dimension Cachée), a saber: o autocarro em Sicilian Carousel e o avião em Paradise News e Un aller simple, os narradores observam o Outro, o turista, oriundo do mesmo local, mas com uma concepção de viagem diferente da nossa. Quando, no decurso da viagem, se abrem pontos de fuga, contactam com o Outro, o autóctone. Porém, em todas as narrativas se verifica que, afinal, o Outro - turista e autóctone - é como nós.

Jean-Pierre Schneider opera, de certa forma, a síntese entre turista e autóctone, no sentido em que passa de viajante vestido de explorador (van Cauwelaert, 1994: 75), que conhece a vulgata turística (linguística, alimentar, ritual) e quer imbuir-se de cor local, numa gradação crescente, que começa na gastronomia (van Cauwelaert, 1994: 91 e 101), passa pela rejeição dos hotéis de luxo em favor da apologia dos alojamentos "chez l'habitant" e termina na adopção de comportamentos de risco que o conduzem à morte.

A dado momento, surge uma personagem feminina que constitui o exacto contraponto de Schneider. Trata-se de uma guia que, na sequência de uma sublevação do grupo de turistas que acompanha, os abandona, sendo contratada pela dupla AzizSchneider. A loura Valérie d'Armeray Villeneuve é natural de Marrocos, usa uma linguagem despudorada e tem um comportamento sexual liberal. Schneider, que afirma "redoute[r] presque autant la banalité que le lirisme" (van Cauwelaert, 1994: 94), mas que é banal e lírico, sonha com uma Valérie nos antípodas do que ela (van Cauwelaert, 1994: 86) realmente é e interpreta erroneamente o comportamento e o discurso da guia (van Cauwelaert, 1994: 95).

Até certo ponto, Valérie também é o oposto especular de Aziz, porquanto, em termos académicos, tem formação superior. Com o seu patronímico genuíno, é, de forma igualmente genuína, uma marroquina que fala árabe. O sistema de personagens da narrativa configura, assim, um circuito interno, em que (i) o cigano é, sucessivamente, um gadjo, um francês e um marroquino; (ii) o árabe ilegal é europeu e só fala francês; (iii) a caucasiana é marroquina e fala árabe; (iv) a d'Armeray de Villeneuve é uma mulher desassombrada; (v) o expatriado torna-se turista no pretenso país de origem; (vi) o desenraizado é acolhido pela família que Schneider rejeitara; (vii) o aspirante a escritor nunca escreverá senão rascunhos e (ix) o iletrado tornar-se-á plumitivo.

Un aller simple é, das três narrativas em apreço, aquela em que os turistas são objecto de uma crítica mais feroz, uma paródia a uma realidade não artística compartilhada pelos leitores. O mesmo sucede em Paradise News, mas não em Sicilian Carousel, onde 
surgem apenas breves sátiras. Embora as diferentes formas de viajar não constituam verdadeiros hipotextos, estes três autores inserem de forma explícita na narrativa principal outros textos alusivos à temática da viagem: panfletos turísticos (van Cauwelaert, 1994: 64); textos literários de índole variada, em Durrell e Lodge; textos científicos sobre turismo, em Lodge; e textos sobre comportamento de grupo em Didier van Cauwelaert. Durrell e Lodge aludem explícita e criticamente ao Club Méditerranée. Lodge declina em vários tons o tema do paraíso e Cauwelaert faz-Ihe uma alusão en passant. Em maior ou menor grau, os três autores, pela voz de diferentes narradores, rejeitam o circuito organizado como forma de viagem.

Se uma crítica comum às três obras consiste na falta de autenticidade, é por esta via que o circuito turístico surge parodiado em Un aller simple. A genuinidade do que se vê, bem assim como do que se compra. O que desencadeia a ruptura entre a guia e o grupo são as compras, souvenirs e contrafacções de marcas francesas. Num apontamento sobremaneira verosímil, que já tínhamos presenciado em Sicilian Carousel, a guia conduz os turistas, que empreendem um tour-express do Magrebe em seis dias, a uma loja, a da esquerda. Por cansaço, por espírito de contradição (de que encontramos inúmeros exemplos nas duas outras obras) o grupo da Morocco Tours revolta-se e decide ir a outra loja, a da direita. Entretanto, chega um autocarro idêntico, com um grupo em tudo semelhante, excepto no nome: Oasis Travel. Ora, o guia destes excursionistas tinha um acordo com a loja da direita e o conflito estala, pois todos querem ir para a loja da direita. A guia tenta dissuadi-los, mas o grupo subleva-se. Valérie insulta-os e abandona-os, sendo acolhida, como já referimos, por Aziz. É assim que ela se torna a guia da dupla AzizSchneider. A escolha desta profissão deve-se a razões práticas, pois Valérie prepara uma tese em sociologia sobre a agressividade em grupo. Tal como reiteradas vezes afirmámos a propósito de Lodge e Durrell, também aqui a sustentação teórica da investigação de Valérie tem um referente científico verificável, os trabalhos do académico Konrad Lorenz. Assim, verifica-se que os três autores recorrem a diferentes auctoritas para conferir verosimilhança à crítica a este subtipo de viagem. É difícil, senão impossível, conceber um leitor que, após a leitura das três obras, não rejeite o circuito turístico como uma forma espúria da viagem.

As três narrativas em análise rejeitam, num crescendo de virulência, a viagem organizada. Verifica-se, pois, que o imaginário do grand tour se mantém, embora se revista de novas formas. De facto, seria impossível recriar o modo como William Beresford e os seus contemporâneos se deslocavam. Actualmente, assistimos à emergência de novas formas de turismo cujo objectivo é conferir aos seus cultores a sensaçâo de que se distinguem dos demais, numa progressão que, actualmente, ultrapassa as barreiras do planeta Terra, culminando no turismo espacial. 


\section{Bibliografia}

BAUDRILLARD, Jean (1991). Simulacros e simulação. Lisboa: Relógio d’Água.

BRETÉCHER, Claire (2007). Tourista. Paris: Dargaud.

BRIS, Michel le (1997). “Écrivain-voyageur”. In: Magazine littéraire, no 353, avril 1997, pp. 24-28.

BRIS, Michel le (2004). "Une littérature-monde". In: Magazine littéraire, № 432, juin 2004, pp. 58-62

DIDIER, van Cauwelaert (1994). Un aller simple. Paris: Albin Michel.

DURRELL, Lawrence (1977). Sicilian Carousel. New York: Marlowe\&Company.

FouCAULT, Michel (1984). "Des espaces autres". In: Architecture, Mouvement, Continuité, no 5, pp. 4649.

HALL, Edward T. (1971). La dimension cachée. Paris: Éditions du Seuil.

LeVI-StRauss, Claude (1986). Tristes Trópicos. Lisboa: Edições 70.

LIPOVETSKY, Gilles (2007). A Felicidade paradoxal. Ensaio sobre a sociedade o hiperconsumo. Lisboa: Edições 70.

LODGE, David (1992). Paradise News. London: Penguin Books. 